\title{
Evaluation of Antinociceptive and Neurotoxic Effects of Intrathecal Dexmedetomidine in Rats
}

\author{
Özgü İsgüzar ${ }^{1}$, Sibel Barış ${ }^{1}$, Ayhan Bozkurt² ${ }^{2}$ Bilge Can ${ }^{3}$, Sırrı Bilge ${ }^{4}$, Hatice Türe ${ }^{1}$ \\ ${ }^{1}$ Department of Anesthesiology, Faculty of Medicine, Ondokuz Mayıs University, Samsun, Turkey \\ ${ }^{2}$ Department of Physiology, Faculty of Medicine, Ondokuz Mayıs University, Samsun, Turkey \\ ${ }^{3}$ Department of Pathology, Faculty of Medicine, Ondokuz Mayıs University, Samsun, Turkey \\ ${ }^{4}$ Department of Pharmacology, Faculty of Medicine, Ondokuz Mayıs University, Samsun, Turkey
}

\begin{abstract}
Objective: Dexmedetomidine has been reported to produce analgesia after intrathecal administration. In the present study the $\alpha 2$-adrenoceptor agonist dexmedetomidine was evaluated for its potential spinal neurotoxic effects.

Material and Methods: Three days after intrathecal cannulation, rats were administered either dexmedetomidine $(3 \mu \mathrm{g} / 30 \mu \mathrm{L}$, i.t.) or saline ( $30 \mu \mathrm{L}$, i.t.). Antinociceptive, sedative and motor effects of intrathecal administrations of dexmedetomidine or saline were evaluated during 90 min. The tail-flick and hot plate tests were used to assess the thermal nociceptive threshold. Seven days after drug administration, animals were sacrified and spinal cords
\end{abstract} were evaluated for histopathological changes by light microscopy.

Results: Dexmedetomidine administered intrathecally produced antinociception. Antinociception was accompanied by immediate sedation and loss of placing-stepping reflexes that lasted over $40 \mathrm{~min}$ in all dexmedetomidine administered rats. In all rats, microscopic examination revealed mild gliosis and minimal infiltration of inflamatory $r$ cells in posterior white matter. Mild (total score 4-6) histopathologic lesions were seen in four animals in dexmedetomidine adminisered rats, but there was no statistically significant difference when compared with the saline administered rats.

Conclusion: We observed that intrathecal injections of dexmedetomidine at the dose of $3 \mu \mathrm{g} / 30 \mu \mathrm{L}$ produce antinociception but did not cause any histopathological sign of injury in the spinal cord.

Key Words: Dexmedetomidine, intrathecal, neurotoxicity, histopathology, rat

Received: 16.02.2012 Accepted: 04.05.2012

\section{Introduction}

Several agents such as opioids, $\alpha_{2}$-adrenoceptor agonists, benzodiazepines, magnesium, and neostigmine are given intrathecally either alone or in combination with local anesthetics for acute and chronic pain relief. Most of them are well investigated for their neurotoxic effects on the medulla spinalis or other central nervous system tissues. Dexmedetomidine is a potent $\alpha_{2}$-adrenoceptor agonist with higher receptor binding affinity when compared with other $\alpha_{2}$ agonists, and produces strong spinal antinociception in animal models (1-4).

However, there is no report related to neurotoxic effects produced by intrathecal dexmedetomidine administration. Thus, the neurotoxic effects of dexmedetomidine need to be clarified before its acceptance as a safe spinal analgesic in humans. The aim of this study was to investigate the neurotoxic effects of intrathecal dexmedetomidine at an antinociceptive dose in rats.

\section{Material and Methods}

All experiments were approved by the Institutional Animal Care and Use Committee and adhered to the guidelines of the Committee for Research and Ethical Issues of the Interna- tional Association for the Study of Pain. Twenty male Wistar rats, weighing 250-300 g, 12-16 weeks were used. All procedures were performed between 08:00 A.M. and 11:30 A.M. The rats were kept in different cages and maintained in a 12-h light/dark cycle at a room temperature of $21 \pm 2^{\circ} \mathrm{C}$ with water and food freely available.

Fasting animals were anesthetized with ketamine 100 $\mathrm{mg} / \mathrm{kg}$ intraperitoneally. Catheters were placed intrathecally with the method described by Yaksh and Rudy (5). Rats were placed in a stereotactic apparatus. The occipitocervical region was prepared and the atlantooccipital membrane was cannulated with a $28 \mathrm{G}$ polyethylene microcatheter with stylet (Portex, styletted microcatheter, UK), and catheters were advanced $8.5 \mathrm{~cm}$ caudally (which left the tip of the catheter in the intrathecal space at the level of $L_{1-2}$ ) to the level of the lumbar enlargement. The correct location of the catheter in the subarachnoid space was verified by the presence of cerebrospinal fluid in the catheter lumen. The catheter was fixed in the subcutaneous tissue and stabilized to the heads of the rats with dental acrylic and the skin was sutured. Lumens of the catheters were washed with $10 \mu \mathrm{L}$ of physiologic saline, and the proximal end of the catheter was connected to a screw connector. 
When the rats recovered from anesthesia they were returned to their cages. All rats were given antibiotics intraperitoneally (30 mg/kg ampicilline) after catheterization. Neurologic injury associated with the use of intrathecal catheter was evaluated after recovery from anesthesia. Paraplegia and absent flexion reflex of both the lower extremities following painful stimuli on the toes of the animals were accepted as positive signs of neurological injury. Any animals exhibiting signs of a neurological or motor deficit were eliminated from the study. Animals with correctly placed catheters were allowed to recover for 3 days after the surgical procedure before nociceptive testing.

\section{Experimental design}

To eliminate the diurnal change, all tests were done at 09:00-12:00 A.M. Three days after catheterization, the antinociceptive, motor and sedative effects of dexmedetomidine and saline were assessed before and 5, 10, 20, 30, 40, 60, $90 \mathrm{~min}$ after injections in a random fashion. Rats in the study group were given dexmedetomidine (Precedex; Hospira, $100 \mu \mathrm{g} / \mathrm{mL}$ ) $3 \mu \mathrm{g} / 30 \mu \mathrm{L}$, and the control group was given 30 $\mu \mathrm{L} 0.9 \%$ saline intrathecally, and finally lumens of the catheters were washed with $10 \mu \mathrm{L}$ saline.

The tail-flick and hot plate tests were used to assess the thermal nociceptive threshold. During the tail-flick test, the tail was immersed in a warm bath $\left(55 \pm 0.5^{\circ} \mathrm{C}\right)$ until tail withdrawal (flicking response) or signs of struggle were observed (cut-off time $12 \mathrm{sec}$ ). The hot plate test was performed to assess the effects of dexmedetomidine on the thermal nociceptive threshold (UgoBasile, Verase, Italy). Rats were individually placed on a $55 \pm 0.5^{\circ} \mathrm{C}$ hot plate. The latency of hind-limb withdrawal was measured. In the absence of a response, the animals were removed from the hot plate at $60 \mathrm{sec}$ to minimize tissue injury, and a $60 \mathrm{sec}$ latency was assigned as the response. The values were converted to percent maximum possible effect (MPE):

MPE $\%=$ (postdrug value - baseline value) / (cut-off valuebaseline value) $\times 100$

Sedation was quantified with a sedation score determined by the response to light touch with a fingertip to the rat's whiskers (2=awake, fully responsive to surroundings, $1=$ not responsive to surroundings, response to whisker stimulation, $0=$ unresponsive to whisker stimulation) (6).

The motor function of rats was assessed using the placingstepping and righting reflexes. The observed responses were graded according to the system used by Yamamoto et al. (7) To quantify the evaluation of motor functions, both tasks were scored on a scale of 0-2 in which $0=$ absence of function and $2=$ normal motor functions. Animals that were able to perform the motor tasks but did so more slowly than normal animals were assigned a score of 1 .

\section{Histopathologic evaluation}

Seven days after drug injection, the animals were terminally anesthetized and then the perfusion fixation method was applied with $10 \%$ formaldehyde. The spinal cord, thoracic and lumbar segments were dissected out with bilateral laminectomy and placed in $4 \%$ neutral formalin for 3 days at room temperature. After fixation, two transverse segments of spinal cord (one from the catheter tip level and the second segment from $0.5 \mathrm{~cm}$ distal to the first level) were embedded in parafin. $8 \mu \mathrm{m}$ sections were stained with hematoxyline-eosin and luxolfast blue myelin staining, and examined by light microscopy. Histopathologic evaluation was made in random order by a pathologist blinded to the study groups. Particular attention was given to the spinal cord parenchyma at a magnification of 40X-400X. Presence of the four following histopathologic lesions, which are indicative for neuroglial damage, were assessed separately; (1) neuronal degeneration such as; ischemic neurons identified by increased cytoplasmic eosinophilia with loss of Nissle substance and pyknotic nuclei, and central chromatolysis identified by round shaped cytoplasm with loss of Nissl substance from the central part of the cell and eccentric nuclei and myelin loss, edema, gliosis, and infiltration of inflammatory cells $(2-4,8,9)$.

The scoring system of Koizumi et al. (10) was modified. Histopathologic lesions were evaluated separately and graded semiquantitavely on a 0-1-2 scale (0: absence of histopathologic findings, 1: focal, 2: diffuse) for each histopathologic parameter. A score of 0-3 was considered as minimal, 4-6 mild, and 7-8 severe histopathologic change.

\section{Statistics analysis}

Statistical analysis was performed using SPSS (Version 13.0) for Windows. The results are given as mean \pm SD. Hot plate and tail-flick data were analyzed by the Kruskal-Wallis test followed by Mann-Whitney U test. The frequency (i.e.motor and sedation scores, and histopathological scores) in each group was analyzed by the chi-square test, and the Fisher's exact test was used where the minimum expected count is less than five. Values of $p<0.05$ were considered statistically significant.

\section{Results}

One rat in the saline group developed hind-limb palsy after catheterization, but before saline administration, and was excluded from the study. A total of 19 rats were analyzed. Dexmedetomidine administered intrathecally produced antinociception for 40-60 min as represented by increased MPE \% of hot plate and tail-flick (Figure 1 and 2). However, no animal lost the righting reflex during $90 \mathrm{~min}$ (Table 1). Additionally, antinociception was accompanied by immediate sedation and loss of placing-stepping reflexes that lasted over $40 \mathrm{~min}$ in all dexmedetomidine administered rats.

Necropsy did not reveal evidence of a gross pathology. During postmortem dissection, all catheters were observed to lie within the intrathecal space at the level of the lumbar enlargement. After necropsy, all the catheters were removed and flushed with saline. None of the catheters showed a sign of leak and occlusion 7 days after the catheterization. There was no evidence of spinal cord compression.

In all groups of rats, microscopic examination revealed mild gliosis and minimal infiltration of inflamatory cells in the posterior white matter. Edema, observed as a mild parenchymatous swelling of the white matter, was found in most animals, therefore we thought these changes were due to catheterization. We did not observe necrosis or demyelination area in either group. Mild (total score 4-6) histopathologic lesions 


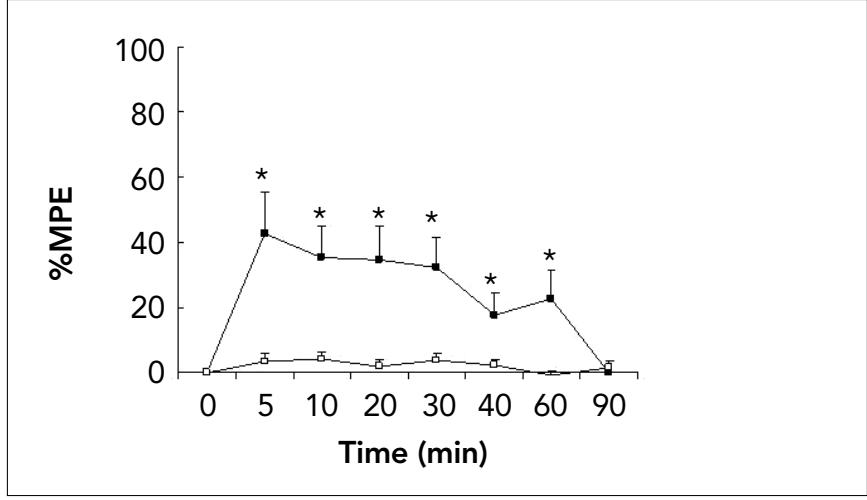

Figure 1. Effect of intrathecal injection of $30 \mu \mathrm{L}(3 \mu \mathrm{g}) \mathrm{dex}-$ medetomidine (closed square) and $30 \mu \mathrm{L}$ saline (open square) in hot plate test on the time course. The percent of maximum possible effect defined as: (postdrug hot plate latency - basal latency) / (cutoff latency- basal latency) X 100\% ${ }^{*} p<0.05$ vs. saline group

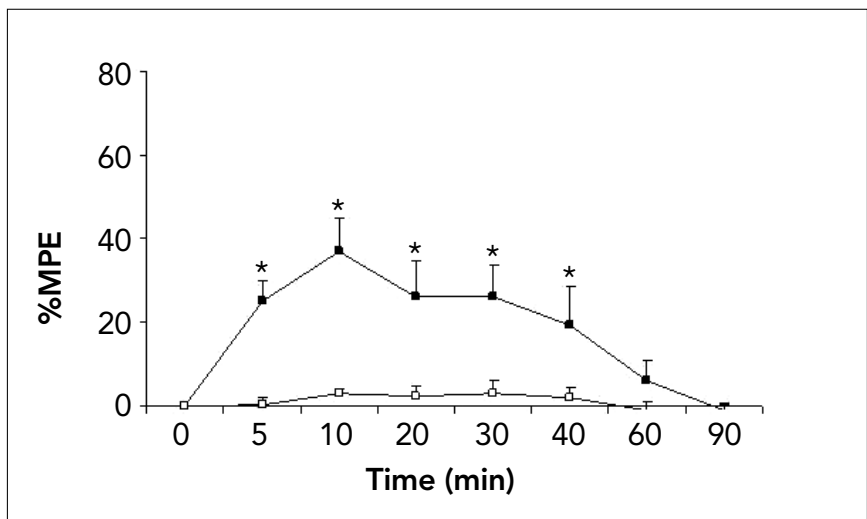

Figure 2. Effect of intrathecal injection of $30 \mu \mathrm{L}(3 \mu \mathrm{g})$ dexmedetomidine (closed square) and $30 \mu \mathrm{L}$ saline (open square) in the tail-flick test on the time course. The percent of maximum possible effect defined as: (postdrug tail immersion latency - basal latency) / (cut-off latency- basal latency) $X$ $100 \%$. * $p<0.05$ vs. saline group. were seen in four animals in the study group but there were no statistically significant differences when compared with the control group (Table 2). Severe histopathologic changes with abcess formation were seen only in one rat in the control group, probably resulting as a complication of catheterization.

\section{Discussion}

After demonstration of alpha ${ }_{2}$-adrenoceptors in the dorsal horn of the spinal cord and in multiple areas of the brain, alpha ${ }_{2}$-adrenergic agonists, such as clonidine and dexmedetomidine, have been used spinally and systemically to produce antinociceptive effects in different pain modalities in animals and humans $(11,12)$. Dexmedetomidine exerts its antinociceptive actions in the spinal cord by hyperpolarizing the membrane potentials of substantia gelatinosa neurons by activation of $\mathrm{K}^{+}$ channels through $\alpha_{2 A^{-}}$and $\alpha_{2 C^{-}}$adrenoceptors (13). One recent study demonstrated the harmful effects of dexmedetomidine $(10 \mu \mathrm{g})$ on the myelin sheaths in the white matter when administered via the epidural route in rabbits (14). In this study, 5 and $10 \mu \mathrm{g}$ epidurally administered dexmedetomidine caused demyelinization of the oligodendrocytes in the white matter. Before using a drug via the intrathecal route in humans, potential spinal neurotoxicity should be investigated carefully in animals. However, Kanazi et al. (15) used $3 \mu \mathrm{g}$ spinal dexmedetomidine for evaluating as an adjuvant analgesic to bupivacaine.

Table 2. Histopathologic evaluation of groups ( $n$ ), $p>0.05$

\begin{tabular}{|c|c|c|c|}
\hline GROUP & $\begin{array}{l}\text { Nonspecific } \\
\text { changes }\end{array}$ & $\begin{array}{c}\text { Mild } \\
\text { histopathologic } \\
\text { lesions }\end{array}$ & $\begin{array}{c}\text { Severe } \\
\text { histopathologic } \\
\text { lesions }\end{array}$ \\
\hline $\begin{array}{l}\text { Dexmedetomidine } \\
\text { group }(n=10)\end{array}$ & e & 4 & 0 \\
\hline $\begin{array}{l}\text { Saline group } \\
(n=9)\end{array}$ & 7 & 1 & $1 *$ \\
\hline \multicolumn{4}{|c|}{$\begin{array}{l}\text { Frequency (number of rats in each group) of histopathologic changes observed } \\
\text { within groups }\end{array}$} \\
\hline
\end{tabular}

Table 1. Dexmedetomidine induced motor effects and sedation in rats. Although the righting reflexes were preserved until the end of the 90 min period in all animals, loss of placing-stepping reflex and increased sedation lasting over 40 minutes ocurred after dexmedetomidine administration

\begin{tabular}{|c|c|c|c|c|c|c|c|c|}
\hline & & \multicolumn{7}{|c|}{ Evaluation Time (min) } \\
\hline & & 5 & 10 & 20 & 30 & 40 & 60 & 90 \\
\hline \multirow{2}{*}{$\begin{array}{l}\text { Placing score } \\
2 / 1 / 0^{\mathrm{a}}\end{array}$} & Dexmedetomidine $(n=10)$ & $0 / 10 / 0 * c$ & $0 / 10 / 0 *$ & $0 / 10 / 0 *$ & $0 / 10 / 0 *$ & $0 / 10 / 0 *$ & $10 / 0 / 0$ & $10 / 0 / 0$ \\
\hline & Saline $(n=9)$ & 9/0/0 & $9 / 0 / 0$ & $9 / 0 / 0$ & $9 / 0 / 0$ & $9 / 0 / 0$ & $9 / 0 / 0$ & $9 / 0 / 0$ \\
\hline \multirow{2}{*}{$\begin{array}{l}\text { Righting score } \\
2 / 1 / 0^{a}\end{array}$} & Dexmedetomidine $(n=10)$ & $10 / 0 / 0$ & $10 / 0 / 0$ & $10 / 0 / 0$ & $10 / 0 / 0$ & $10 / 0 / 0$ & $10 / 0 / 0$ & $10 / 0 / 0$ \\
\hline & Saline $(n=9)$ & $9 / 0 / 0$ & $9 / 0 / 0$ & $9 / 0 / 0$ & $9 / 0 / 0$ & $9 / 0 / 0$ & $9 / 0 / 0$ & $9 / 0 / 0$ \\
\hline \multirow{2}{*}{$\begin{array}{l}\text { Sedation score } \\
2 / 1 / 0^{b}\end{array}$} & Dexmedetomidine $(n=10)$ & $0 / 10 / 0^{\star}$ & $0 / 10 / 0 *$ & $0 / 10 / 0 *$ & $0 / 10 / 0^{*}$ & $0 / 10 / 0^{*}$ & $10 / 0 / 0$ & $10 / 0 / 0$ \\
\hline & Saline $(n=9)$ & 9/0/0 & 9/0/0 & 9/0/0 & 9/0/0 & 9/0/0 & $9 / 0 / 0$ & $9 / 0 / 0$ \\
\hline \multicolumn{9}{|c|}{ aFor placing and righting, a score of 2 is normal, 0 is absent } \\
\hline \multicolumn{9}{|c|}{ bor sedation, 2 is absence of sedation, 0 is deep sedation } \\
\hline \multirow{2}{*}{\multicolumn{9}{|c|}{$\begin{array}{l}\text { " In each value cell, the numbers separated with dashes denote the number of animals for each score; e.i. a notation of } 0 / 10 / 0 \text { means } 10 \text { animals } \\
\text { scored } 1 \text { and none scored } 0 \text { or } 2\end{array}$}} \\
\hline & & & & & & & & \\
\hline \multicolumn{9}{|c|}{ *Differences between dexmedetomidine and saline groups significant $(p<0.0001)$} \\
\hline
\end{tabular}


Intrathecal dexmedetomidine doses of $3 \mu \mathrm{g}$ have previously been reported to produce antinociceptive effects according to hot plate and tail flick latencies in rats $(2,16)$. Although they did not find an antinociceptive effect with 1 $\mu \mathrm{g}$ dexmedetomidine, prolonged and profound antinociception was experienced with $10 \mu \mathrm{g}$ dexmedetomidine. Similarly, Kalso et al. (2) showed that 3 and $6 \mu \mathrm{g}$ dexmedetomidine produced a maximal increase in the tail-flick latencies within 10 min. Therefore, we used the previously reported minimum antinociceptive dose of dexmedetomidine of $3 \mu \mathrm{g}$ in rats. In our study, significant antinociceptive effect was achieved in the hot plate and tail flick tests in the dexmedetomidine group during the first 60 and $40 \mathrm{~min}$, respectively. In addition, antinociception was accompanied by sedation and minimal motor impairment, and that lasted approximately $40 \mathrm{~min}$.

Intrathecal application of drugs carries the risk of neurological impairment and this may be manifested as histological, physiological or behavioral derangements. The reasons for neurological impairment may be direct trauma to the spinal cord or roots during spinal anesthesia or catheterization, exposure to various drugs (spinal local anesthetic agents, spinal analgesics, adjuvants) or preservatives (17). As previously discussed, clinical and laboratory investigations about intrathecal or epidural clonidine have demonstrated that clonidine does not produce significant neurotoxicity when administered at clinically relevant doses and it is accepted as a safe and effective drug for pain therapy (18). Dexmedetomidine has similar properties to clonidine and a greater affinity for alpha ${ }_{2}$-receptors. In addition, the antinociceptive properties of spinally administered dexmedetomidine seem to be superior to clonidine (19). As the relative alpha ${ }_{2} /$ alpha ${ }_{1}$ adrenoceptor selectivity ratio of dexmedetomidine is higher than clonidine, dexmedetomidine causes fewer side effects mediated by alpha ${ }_{1}$ adrenoceptor activation than clonidine (20). For these reasons, dexmedetomidine may be expected to be more suitable for spinal or epidural analgesia than other alpha ${ }_{2}$ agonists.

In a study presented by Gordh et al., (9) the spinal neurotoxicity of alpha ${ }_{2}$ adrenoceptors agonist clonidine and guanfacine was evaluated in rats. In this study, although the number of mononuclear inflammatory cells was evident close to the catheter, the inflammatory reaction was less pronounced in the rats in which an intrathecal catheter left insitu for 14 days had been inserted but no injections had been given. Durant et al. (21) reported that chronically implanted epidural catheters in rats were surrounded by several layers of red blood cells during the first day after insertion, which were followed by edema and proliferating connective fibers. All catheters were surrounded by lymphocyte and connective tissue after 10 days of catheterization. Similarly in our study, a direct traumatic injury caused by catheterization may be the reason for the observed similar pathological lesions in both groups.

\section{Conclusion}

We observed that intrathecal injections of dexmedetomidine at the dose of $3 \mu \mathrm{g} / \mathrm{rat}$ produce antinociception but did not cause any histopathological sign of injury in the spinal cord. In general, toxicity increases with excessive chemical concentrations, therefore higher doses should be evaluated for neurotoxicity by further research.

\section{Conflict of Interest}

No conflict of interest was declared by the authors.

\section{References}

1. Yaksh TL. Pharmacology of spinal noradrenergic systems which modulate spinal nociceptive processing. Pharmacol Biochem Behav 1985;22:845-58. [CrossRef]

2. Kalso EA, Poyhia R, Rosenberg PH. Spinal antinociception by dexmedetomidine, a highly selective $\alpha 2$-adrenergic agonist. Pharmacol Toxicol 1991;68:140-3. [CrossRef]

3. Kendig JJ, Savola MK, Woodley SJ, Maze M. Alpha 2-adrenoreceptors inhibit a nociceptive response in neonatal rat spinal cord. Eur J Pharmacol 1991;192:293-300. [CrossRef]

4. Stevens CW, Brenner GM. Spinal administration of adrenergic agents produces analgesia in amphibians. Eur J Pharmacol 1996;316:205-10. [CrossRef]

5. Yaksh TL, Rudy TA. Chronic catheterization of the spinal subarachnoid space. Physiol Behav 1976;17:1031-6. [CrossRef]

6. Archer DP, Lamberty Y, Wang B, Davis MJ, Samanani N, Roth SH. Levetiracetam reduces anesthetic-induced hyperalgesia in rats. Anesth Analg 2007;104:180-5. [CrossRef]

7. Yamamoto T, Nozaki-Taguchi N, Chiba T. Analgesic effect of intrathecally administered orexin-A in the rat formalin test and in the rat hot plate test. Br J Pharmacol 2002;137:170-6. [CrossRef]

8. Hodgson PS, Neal JM, Pollock JE, Liu SS. The neurotoxicity of drugs given intrathecally (spinal). Anesth Analg 1999;88:797-809. [CrossRef]

9. Gordh T Jr, Post C, Olsson Y. Evaluation of the toxicity of subarachnoid clonidine, guanfacine, and substance $P$-antagonist on rat spinal cord and nerve roots: Light and electron microscopic observations after chronic intrathecal administration. Anesth Analg 1986;65:1303-11.

10. Koizumi Y, Matsumoto M, Yamashita A, Tsuruta S, Ohtake T, Sakabe T. The effects of an AMPA receptor antagonist on the neurotoxicity of tetracaine intrathecally administered in rabbits. Anesth Analg 2006;102:930-6. [CrossRef]

11. $\mathrm{Xu} M$, Kontinen VK, Kalso E. Effects of radolmidine, a novel alpha2adrenergic agonist compared with dexmedetomidine in different pain models in the rat. Anesthesiology 2000;93:473-81. [CrossRef]

12. Eisenach JC, DuPen S, Dubois M, Miguel R, Allin D. Epidural clonidine analgesia for intractable cancer pain. The Epidural Clonidine Study Group. Pain 1995;61:391-9. [CrossRef]

13. Ishii $H$, Kohno T, Yamakura $T$, Ikoma M, Baba H. Action of dexmedetomidine on the substantia gelatinosa neurons of the rat spinal cord. Eur J Neurosci 2008;27:3182-90. [CrossRef]

14. Konakci S, Adanir T, Yilmaz G, Rezanko T. The efficacy and neurotoxicity of dexmedetomidine administered via the epidural route. Eur J Anaesthesiol 2008;25:403-9. [CrossRef]

15. Kanazi GE, Aouad MT, Jabbour-Khoury SI, Al Jazzar MD, Alameddine MM, Al-Yaman R, et al. Effect of low-dose dexmedetomidine or clonidine on the charactheristics of bupivacaine spinal block. Acta Anaesthesiol Scand 2006;50:222-7. [CrossRef]

16. Fisher B, Zornow MH, Yaksh TL, Peterson BM. Antinociceptive properties of intrathecal dexmedetomidine in rats. Eur J Pharmacol 1991;192:221-5. [CrossRef]

17. Hodgson PS, Neal JM, Pollock JE, Liu SS. The neurotoxicity of drugs given intrathecally (spinal) Anesth Analg 1999;88:797-809. [CrossRef]

18. Eisenach JC, De Kock M, Klimscha W. Alpha (2)-adrenergic agonists for regional anesthesia: A clinical review of clonidine (1984-1995). Anesthesiology 1996;85:655-74. [CrossRef]

19. Takano Y, Yaksh TL. Relative efficacy of spinal alpha-2 agonists, dexmedetomidine, clonidine and ST-91, determined in vivo by using $\mathrm{N}$-ethoxycarbonyl-2-ethoxy-1,2-dihydroquinoline, an irreversible antagonist. J Pharmacol Exp Ther 1991;258:438-46.

20. Virtanen R, Savola JM, Saano V, Nyman L. Characterization of the selectivity, specificity and potency of medetomidine as an alpha 2-adrenoceptor agonist. Eur J Pharmacol 1988;150:9-14. [CrossRef]

21. Durant PA, Yaksh TL. Epidural injections of bupivacaine, morphine, fentanyl, lofentanil, and DADL in chronically implanted rats: a pharmacologic and pathologic study. Anesthesiology 1986;64:43-53. [CrossRef] 